\title{
Studies on the Structure of Vaccinia Virus
}

\author{
BY J. C. N. WESTWOOD, W. J. HARRIS, H. T. ZWARTOUW, \\ D. H. J. TITMUSS AND G. APPLEYARD \\ Microbiological Research Establishment, Porton, Salisbury
}

(Received 18 June 1963)

\begin{abstract}
SUMMARY
Vaccinia virus has been examined with the electron microscope by several techniques in conjunction with experimental modifications of structure. Negative staining revealed that over $80 \%$ of the virus in highly purified preparations were particles which appeared to have a beaded surface like a mulberry and were termed $\mathbf{M}$ forms. The beading was formed by loops of thread-like structures $90 \AA$ wide which were themselves double helices formed from two $30 \AA$ strands coiled to a $120 \AA$ pitch. Twenty per cent or less of the particles appeared as larger more electrondense bodies with a capsule of complex structure; these have been termed C forms. Experimental interconversion of the two forms showed that both were structurally mature virus. The relationship of structures seen in $\mathbf{C}$ forms to those revealed by thin sectioning is considered. Experimental findings and the results of shadowing and replica examinations indicate the presence of a superficial protein layer of antigenic material not revealed by negative staining. The relationship of this layer to the structure of the virus and the nature of the ribbon structure of the $M$ form are discussed.
\end{abstract}

\section{INTRODUCTION}

Electron microscopic examination of shadowed preparations of mature vaccinia virus has shown the virus to be a brick-shaped particle thickened at the centre and at the four corners and possessing a beaded surface. This appearance was well shown by Dawson \& McFarlane (1948) who used virus purified by salt flocculation, fixed with osmic acid and shadowed with gold. Examination of thin sections has shown the virus to possess a relatively complex structure with an outer multilayered membrane surrounding a biconcave nucleoid in the concavities of which are situated a pair of lens-shaped lateral bodies which are responsible for the central thickening of the particle (Morgan, Ellison, Rose \& Moore, 1954; Peters, 1956; Epstein, $1958 a, b$; Dales \& Siminovitch, 1961). Recently the negative-staining technique (Brenner \& Horne, 1959) has revealed the presence of structures of about $90 \AA$ width which were interpreted as hollow rods by Herzberg, Kleinschmidt, Lang \& Reuss (1961), as predominantly spherical structures sometimes running together to form cords by Noyes $(1962 a, b)$, and as long tubular threads by Nagington \& Horne (1962). The latter workers showed that in the virus of contagious pustular dermatitis (orf) these threads were wound around the particle in an orderly manner, but little such order is detectable in the case of vaccinia or canary-pox (Herzberg et al. 1961). Nagington \& Horne also described a second type of particle lacking the thread structure and differing in size from the first type. The present study was 
undertaken in order to give a morphological basis to chemical and antigenic studies. Several techniques of examination have been used on highly purified preparations of mature virus. The results suggest that the use of any one technique alone leads to over-simplification in the interpretation of results.

\section{METHODS}

Virus. A dermal strain of vaccinia virus was grown on rabbit skin as described by Hoagland, Smadel \& Rivers (1940) and purified by density-gradient centrifugation by the method of Zwartouw, Westwood \& Appleyard (1962). The final deposit was suspended for electron microscopy in distilled water, to each litre of which one drop of concentrated ammonia was added to assist dispersal of the virus.

Trypsin. Freshly prepared solutions of Armour crystalline trypsin were used in appropriate experiments.

Electron microscopy. Grids coated with carbon or formvar were used throughout. Virus suspensions inactivated by ultraviolet irradiation were either sprayed on to the grids or were applied by means of a pipette, excess fluid being removed with filter paper. Specimens were examined in the Siemens Elmiskop 1 electron microscope using double condenser illumination with $200 \mu$ condenser aperture and $50 \mu$ objective aperture. $80 \mathrm{kV}$. accelerating voltage was used for negatively stained specimens and $60 \mathrm{kV}$. for all others.

Negative staining. Two per cent $(\mathrm{w} / \mathrm{v})$ potassium phosphotungstate (PTA) at pH 5-6 was used as originally recommended by Brenner \& Horne (1959). Virus was either mixed with the stain in equal volumes and sprayed on to coated grids or was first applied to the grids with a pipette and then stained in situ.

Shadowing. Shadowing was carried out by using a device which permitted shadowing through an aperture at various fixed angles (Harris, 1962). Materials used were gold and palladium, carbon and platinum or carbon alone.

Replicas. Self-shadowed replicas were obtained by the evaporation of carbon on to glass slides on which purified virus had been dried. After stripping, the carbon films were floated on to $2 \% \mathrm{KOH}$ at $60^{\circ}$ to dissolve any adherent virus particles.

\section{RESULTS}

\section{Observations by using negative staining techniques}

Preparations of purified vaccinia virus were shown by negative staining with PTA to contain two types of particle as reported by Nagington \& Horne (1962). In fresh preparations between 80 and $90 \%$ of the virus consisted of particles which had a beaded appearance like a mulberry; these will be referred to as the ' $M$ ' form. The remainder were larger capsulated particles and will be referred to as the ' $C$ ' form. The two forms are shown together in Pl. 1, fig. 1.

$M$ form. The $\mathrm{M}$ form of the virus (Pl. 1, figs. 3, 4, Pl. 2, fig. 6) possessed a beaded surface and a toothed edge. The central thickening could usually be distinguished and the particle bore an obvious similarity to the usual picture of shadowed virus (Pl. 3, fig. 12). The surface beading was usually completely irregular but occasional particles in suitable orientation revealed a regular arrangement of teeth around the margin of the particle, $40-42$ being present at intervals of about $270 \AA$. Despite 
their occasional appearance of regularity there is no basic difference between these marginal serrations and the beading over the remainder of the virus surface. Each tooth is formed from a single loop of a long thread as may be seen in Pl. 1, fig. 3. The appearance at $\mathbf{A}$ in this figure suggests that the thread is arranged as a coil or zig-zag around the edge of the particle, neighbouring teeth being formed from adjacent coils. However, this appearance is probably illusory since, first, other photographs show the threads to run across the body of the virus in an arrangement more like that of orf (Pl. 1, fig. 5) and, secondly, for reasons discussed below, the thread structure must be entirely superficial, being limited to a depth of no more than 100-150 A. While this would not preclude a flat zig-zag it would preclude coiling of the order of size suggested by these particles. It seems more likely that neighbouring teeth are formed from neighbouring threads lying parallel to each other and looping around the virus particle and this is in fact seen to be the case in particles viewed on edge.

As noted by previous workers (Nagington \& Horne, 1962; Herzberg et al. 1961) most threads are about $90 \AA$ wide and frequently appear as double strands suggesting tubes with hollow centres about $30 \AA$ in diameter. The structure, however, appears to be more complex than a simple tube. Owing to the intricacy of their interweaving the threads are seldom seen clearly for more than short distances, though their general course may frequently be traced for many hundred Angstrom units in length. Over short distances, however, they are often seen with sufficient clarity to suggest that they are helical structures, three types of appearance being distinguishable.

(1) An appearance of frank coiling may sometimes be seen, especially at the edge of a particle (Pl. 2, fig. 6, at $\mathrm{A}$, fig. $7 \mathrm{~b}$ and $7 c$ ).

(2) Occasionally a chain-stitch appearance may be distinguished (Pl. 1, fig. 5, at B; Pl. 2, fig. 6, at B).

(3) More frequently, each strand of the thread appears as a series of dots at about $60 \AA$ intervals (Pl. 1, fig. 5, at $\mathrm{C}$ and $\mathrm{C}_{1}$; Pl. 2, fig. 6, at C, fig. 7 a). Occasionally a third row of fainter dots intervenes between the two main series.

The first two appearances directly suggest a helical structure, and the third could be produced by such a structure if each dot represented the point at which the coiled strand turned into the axis of the electron beam, the faint central line of dots being the cross-over points of two interlocking strands (Fig. 1). In Pl. 2, fig. $7 a$, a thread composed of two such series of dots terminates in an open figure of eight in which the terminal coils of the individual strands can be clearly seen. In $\mathrm{Pl}$. 1, fig. 5, at $\mathrm{C}_{1}$, there is a strong suggestion of the individual strands connecting the dots of the two series in the unusually wide left-hand portion of the thread which appears to pass into a thread of more usual width at the right. It can be seen from this and other photographs that there is, in fact, considerable variation in thread width. It would appear, therefore, that each of the long threads which can be distinguished in this type of particle consists of a double-stranded ribbon coiled in its long axis to form a double helix of about $120 \AA$ pitch. In certain photographs detailed examination of the individual $30 \AA$ strands comprising the ribbons shows a regular arcading or barring at about $17 \AA$ interval. This appearance, which does not seem to be either astigmatic or photographic in origin, suggests that each strand may itself be made up of a filament or filaments of 6-10 $\AA$ diameter 
coiled to a $17 \AA$ pitch. The appearance must clearly be treated with the greatest caution since it lies near the theoretical limit of resolution of the instrument even under optimal conditions. However, the suggested structure is not illogical if, as seems likely, the thread structure is protein in nature, since the peptide chain complexes of fibrous proteins are probably about $6-10 \AA$ in diameter (Crick \& Kendrew, 1957). Three kinds of helical structure might then be involved: (1) a peptide helix; (2) the $30 \AA$ strand made up of a coil of one or more of such helices; (3) the $90 \AA$ thread consisting of a double helix made up from two $30 \AA$ strands.

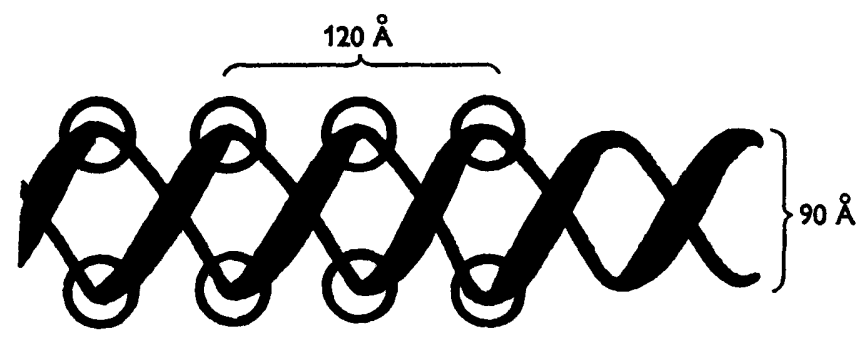

Fig. 1. Suggested structure for the threads of the $M$ form of vaccinia virus. The circles represent the points at which the strands forming the double helix turn into the axis of the electron beam and may show as a series of dots. Compare with PI. 2, fig. $7 a$.

The arrangement of the threads on the virus particle is difficult to determine. In most particles there appeared to be a complex felt-work of interlacing threads, but occasional particles showed the more orderly arrangements already mentioned, particularly in those regions where the marginal serrations can be clearly seen. It seems likely therefore that the basic arrangement is orderly even if its nature cannot be distinguished.

$C$ form. Of the virus particles in a fresh preparation $20 \%$ or less differed from those described above. These $\mathrm{C}$ particles were larger than the $\mathrm{M}$ form, were more electron dense, did not show the ribbon structure and possessed a capsule (Pl. 1 , fig. 1; Pl. 2, fig. 8). The capsule, which was $200-250 \AA$ in thickness, surrounded an inner body of uniform electron density with little or no indication of the central thickening seen in the $\mathbf{M}$ form and in shadowed preparations. The outer surface of the capsule of the $\mathrm{C}$ form showed as a somewhat ragged membrane which was crenated to form teeth at the same intervals as those on the $\mathbf{M}$ form. Its inner surface was smooth, but no definite membrane was distinguished, the capsule being bounded by the outer surface of the smooth inner body. The capsular region was divided into inner and outer portions, the former being subdivided by radially disposed partitions giving an appearance of pallisading (Pl. 1, fig. 1; PI. 2, fig. 8). The partitions responsible for the pallisading were at about 75-80 $\AA$ intervals and could be resolved into double-stranded structures about $45 \AA$ wide, suggestive of tubes with hollow centres (Pl. 2, fig. 8, at A and B; Pl. 3, fig. 10, at A), as suggested by Noyes (1962b).

When the side elevation of the $\mathrm{C}$ form was studied (Pl. 3, figs. 10, 11) it at once became obvious that the outer zone of the capsule corresponded to the outer multilayered membrane, and the smooth inner body to the nucleoid, as seen in thin section (Pl. 1, fig. 2). The pallisaded zone was seen to be integral with the nucleoid 
and followed its contours, while the outer limiting membrane passed over the surface of the lateral body which appeared to lie between this membrane and the pallisaded zone. At each end of the virus particle the nucleoidal structures were within $125 \AA$ of the virus surface; the identity of the pallisaded zones in the side and plan elevations of the virus may be clearly seen from Pl. 3, fig. 10. Except in the region of the lateral bodies, therefore, the nucleoid everywhere approached very close to the virus surface and the superficial structures overlying it were limited to a depth of about $125 \AA$. The surface of the nucleoid underlying the pallisaded zone presented the appearance of a layer about $45 \AA$ thick surrounding a stippled area comprising the nucleoidal body. This layer was not, however, a continuous membrane, but itself appeared as a series of elongated dots at $45 \AA$ interval (Pl. 2, fig. 8, at A) which seemed to be aligned with the partitions of the pallisaded zone and sometimes appeared to be similarly aligned with rows of dots forming parallel 'tubules' in the stippled area of the nucleoid (Pl. 3, fig. 11, at A). However, the nature of the fine structure in the body of the nucleoid is not easily distinguished and there is no indication that stain penetrates beyond its surface in the untreated virus. Thus the nucleoids in Pl. 3, figs. 10, 11, give no hint of the internal structure suggested in the section shown in Pl. 1, fig. 2. Indications of deeper structure are only seen following chemical treatment of the virus; Peters (1962) has obtained very revealing pictures of such structure following alkali treatment.

Relationship of $M$ forms to $C$ forms. The simplest explanation of the relationship between the two forms is that the larger $\mathrm{C}$ form is the complete form of the virus and represents an $M$ particle surrounded by a capsule which masks the thread structure. This explanation was suggested by Nagington \& Horne (1962) who interpreted their Type I particle as the inner disc-shaped body described by Morgan et al. (1954) and now usually termed the nucleoid, the thread structure possibly representing DNA. There are, however, several objections to this interpretation. In the first place, thin sectioning of the virus pellets obtained by centrifugation of the preparations used in the present work showed that all the virus present was structurally mature. Therefore the $\mathbf{M}$ forms, which make up $80 \%$ of fresh preparations, are structurally mature particles. Secondly, the greater electron density of the $\mathrm{C}$ forms (Pl. 1, fig. 1) showed that they were more, and not less, penetrable by stain than the $M$ forms. Thirdly, when measurements of the two forms are compared (Table 1), it is seen that, although the $\mathrm{C}$ forms were on average larger than the $M$ forms, the difference was not adequate to accommodate a $250 \AA$ capsule. The only explanation which appears to fit the observations is that both forms were structurally mature and the differences between them were due solely to differences in the degree of penetration of the stain; that in the $\mathbf{M}$ form the total exclusion of stain from the interior of the virus prevented visualization of the capsule and revealed only superficial structure, while penetration of stain into the C form caused optical obliteration of the superficial $\mathbf{M}$ structure, but revealed internal structure down to the surface of the nucleoid, causing at the same time an overall increase in electron density. This view is in agreement with that expressed by Noyes (1962b) and Dr D. Peters (personal communication). If this explanation be correct then increasing the penetration of stain into the virus should convert M forms to $\mathbf{C}$ forms. The following treatments were found to effect this conversion.

(1) Trypsin. Preparations of virus were incubated with $0.01 \%$ crystalline trypsin 
for $\mathrm{I} \mathrm{hr}$. or longer at $\mathrm{pH}$. A small proportion of particles was converted into forms intermediate between $M$ and $C$, in which both the capsule and residual $M$ structure could be seen. Plate 4, fig. 14, shows a particle in which one corner (at $\mathbf{A}$ ) reveals $\mathbf{C}$ structure with a suggestion of pallisading, while the remainder of the particle is clearly $M$.

(2) Urea. Virus treated with trypsin as above and placed on an electron microscope grid was washed and then inverted on a saturated solution of urea for $15 \mathrm{~min}$. at room temperature. The preparation was again washed and then flooded with PTA. After this treatment $82 \%$ of the virus in one experiment and $96 \%$ in a second was found to be in the $\mathrm{C}$ form (PI. 4, fig. 18). Subsequent experiments showed that urea effected the conversion, without preliminary treatment with trypsin.

(3) Alkali. Virus was placed on electron microscope grids, and washed by inversion on distilled water. A series of such preparations were then inverted for $1 \mathrm{hr}$. at room temperature on glycine buffers ranging from $\mathrm{pH} 9$ to 12.8. After treatment at $\mathrm{pH} \mathrm{11,95 \% ,} \mathrm{and} \mathrm{at} \mathrm{pH} 12,100 \%$, of the virus was found to be in the $\mathrm{C}$ form.

\title{
Table 1. Measurements of $M$ and $C$ forms of vaccinia virus in negatively stained preparations
}

\begin{abstract}
The table compares measurements from untreated virus with those from virus treated in various ways. Measurements were made on photographs taken at $\times 10,000$ magnification and are about $10 \%$ below similar measurements made at $\times 40,000$ and 80,000 .
\end{abstract}

$\begin{array}{llcc}\text { Treatment } & \begin{array}{c}\text { Virus } \\ \text { form* }\end{array} & \begin{array}{c}\text { Length (range) } \\ (\mathrm{m} \mu)\end{array} & \begin{array}{c}\text { Breadth (range) } \\ (\mathrm{m} \mu)\end{array} \\ \text { Nil (control) } & \text { M (40) } & 254(235-280) & 201(167-224) \\ & \text { C (40) } & 270(235-339) & 218(180-262) \\ \text { Trypsin } & \text { M (14) } & 246(230-260) & 187(180-190) \\ \text { Urea } & \text { C (10) } & 252(220-280) & 203(170-230) \\ \text { pH 10 } & \text { C (23) } & 280(245-300) & 219(190-250) \\ \text { pH 10.5 } & \text { M (14) } & 251(240-264) & 199(187-211) \\ & \text { C (14) } & 277(246-303) & 226(205-244) \\ \text { pH 11·0 } & \text { M (15) } & 248(233-261) & 196(182-205) \\ & \text { C (15) } & 277(264-292) & 220(207-250) \\ \text { pH 12.8 } & \text { M (15) } & 239(219-283) & 192(180-209) \\ & \text { C (15) } & 265(259-280) & 212(201-230) \\ \text { Weighted mean } & \text { M (24) } & 240(220-255) & 178(150-190) \\ & \text { M (21) } & 273(250-320) & 211(180-240) \\ \text { Difference: } & \text { C (138) } & 248(219-283) & 192(150-224) \\ & & 271(220-339) & 217(170-262)\end{array}$

* Figures in parentheses denote number of particles measured.

(4) Drying. Quantitative discrepancies in the results of repetitive experiments using these and other techniques of conversion led to a recognition of the fact that desiccation of the virus was alone sufficient to cause the conversion. The resulting problems in standardization of the preparative procedure were therefore investigated and the results will be the subject of a separate paper. These investigations showed 
that not only did desiccation cause conversion to the $\mathbf{C}$ form, but reconstitution of the desiccated virus by soaking in distilled water caused reconversion to the $\mathbf{M}$ form.

(5) Fat solvents. Similar conversion followed treatment with fat solvents such as ethanol, ether, chloroform, acetone and carbon tetrachloride.

These results confirm that the difference between the two normally occurring forms of virus lies in their relative permeability to stain rather than in some gross structural difference between them, but do not indicate the nature of the barrier to PTA penetration into the $M$ form. The difference may reflect relative states of physiological rather than structural maturity, but there is no evidence for this. While the slightly greater size of the $\mathrm{C}$ form might be due to immaturity it seems more likely to be due to swelling as a result of penetration of stain and water. Measurements of the size of particles converted to the $\mathrm{C}$ form as a result of chemical treatment showed that conversion was accompanied by swelling, but the converted particles did not differ in size from those in untreated preparations and the mean size of the unconverted $M$ forms was not altered (Table 1 ). Normally occurring $C$ forms frequently showed some breach in the virus surface which might have permitted the penetration of stain; an experiment showed that mechanical trauma by explosive decompression also converted $\mathbf{M}$ forms into $\mathbf{C}$ forms. It seems probable therefore that $\mathbf{C}$ forms in normal preparations represent virus particles injured or deficient in some way.

From the above findings it follows that, since the thread structure of the $\mathbf{M}$ form is revealed only when stain is totally excluded from the virus particle and is obliterated when stain penetrates, this structure must be entirely superficial. Since, further, the pallisaded zone of the capsule is integral with the nucleoid, the thread structure must be limited to the outer zone of the capsule-in a layer only about $125 \AA$ thick. It cannot therefore be regarded as representing the structure of the virus as a whole.

\section{Observations by using shadowing techniques}

The appearance of osmic acid-fixed gold-shadowed virus has already been mentioned, but the interpretation of the apparent surface beading has always been complicated by the severity of the gold granulation inseparable from this technique. The surface pattern is better seen in preparations shadowed with platinum and carbon (Bradley, 1960) or better still with carbon alone (W. J. Harris, unpublished); the size of the resulting granulation then lies well below that of the surface beading and the nature of the latter is well indicated (Pl. 3, fig. 12). There is a general similarity to the beading and serration shown by negative staining, and the tooth intervals are similar. However, such structure is clearly shown only by virus which has been flocculated with sodium chloride or pre-treated with trypsin and then fixed with osmic acid before shadowing. When live virus, or virus killed by ultraviolet irradiation, was sprayed on to grids precooled with liquid nitrogen (grid temperature, $-150^{\circ}$ ) by a modification of the technique of Williams (1953) and the snapfrozen droplets freeze-dried before shadowing, little indication of surface beading was seen. In fact, when collapse and shrinkage were eliminated, the virus was found to possess a surprisingly smooth surface even when shadowed with gold. On the other hand, if unfixed virus is sprayed at room temperature, the resulting collapse may be extreme and shadowing then reveals the presence of a superficial 
wrinkled structure, possibly a membrane, collapsed down on to an underlying beaded surface (Pl. 4, figs. 16, 17). These results confirm the presence of a beaded structure but indicate that it is normally covered by some substance or structure which gives the virus a smooth surface. This substance is not revealed by negative staining but its presence may occasionally be deduced. For instance the $\mathbf{M}$ form in Pl. 1, fig. 4, and one of the $\mathrm{C}$ forms in Pl. 1, fig. 1 , are seen to be surrounded by the remnants of an envelope such as is rarely seen in purified, but is relatively common in unpurified, preparations. The remnants are separated from the virus particle in a manner which suggests that they overlie a layer of some substance which is completely penetrated by the stain. The protein nature of this substance is suggested by the action of trypsin on the purified virus.

\section{Effect of trypsin}

In experiments to be reported elsewhere Zwartouw et al. (in preparation) showed that suitably controlled treatment with trypsin caused the solution of up to $20 \%$ of the virus-nitrogen, including components having virus immunospecificity. We have obtained similar results without the use of proteolytic enzymes, by prolonged incubation at $37^{\circ}$ of virus suspensions containing $0.1 \%$ sodium azide. In the latter case, although up to $15 \%$ of the virus-protein was released into solution, the infectivity of the virus suspension was not detectably diminished. Morphologically, despite chemical and antigenic evidence of protein release, very little difference was detectable between control virus and treated virus, whether these were examined by negative staining or shadowing techniques. In the absence of trypsin there was no detectable difference, but after trypsin treatment there was a softening of the thread detail seen in negatively stained preparations, though evidence of coiling could still be distinguished and no evidence was seen to suggest the digestion of thread structure (Pl. 4, fig. 15). As already mentioned, increased permeability to phosphotungstic acid was induced in some particles with the production of intermediate forms. In shadowed preparations the surface beading appeared to be more conspicuous but the differences were slight and gave rise to the suspicion that the effects of treatment might be due to the disintegration of a non-infective fraction of the virus population, rather than to the release of protein and antigen equally from all the particles present. Counts on treated and untreated samples, carried out by the method of Backus \& Williams (1950), did not show any decrease in the total number of apparently intact virus particles present after successive hourly periods during $3 \mathrm{hr}$ trypsin treatment; but it is felt that the method may not be sensitive enough for such results to be conclusive.

With this qualification it may be provisionally concluded that vaccinia virus possesses a superficial coating of protein material, which initially lies under a loose envelope, but which becomes exposed in the mature particle by the shedding of this envelope. The coating of protein material is not removed by physical purification procedures and is therefore strongly adsorbed to the virus surface; its initial location beneath an envelope and its antigenic affinities indicate that it is viral in origin and is not contaminating material derived from the host cells. Finally, its release on incubation without concurrent loss of infectivity suggests that it is not an essential part of the virus structure. These results give morphological form to the early 
demonstration by Craigie \& Wishart (1936) that soluble antigens may be leached out of the virus elementary bodies. The concept of vaccinia virus structure which emerges from this study is shown diagrammatically in Fig. 2.

\section{Observations by replica technique}

The surface appearance revealed by the replica technique (Pl. 2, fig. 9) could not be reconciled with that obtained by either the negative-staining or shadowing techniques. Surface beading was not apparent even after trypsin treatment of the virus. Instead, a complex fine structure was discernible with conspicuous pallisading at the virus margin. In the capsular region the surface configuration indicated a stepped collapse, dividing the capsule into inner and outer portions.

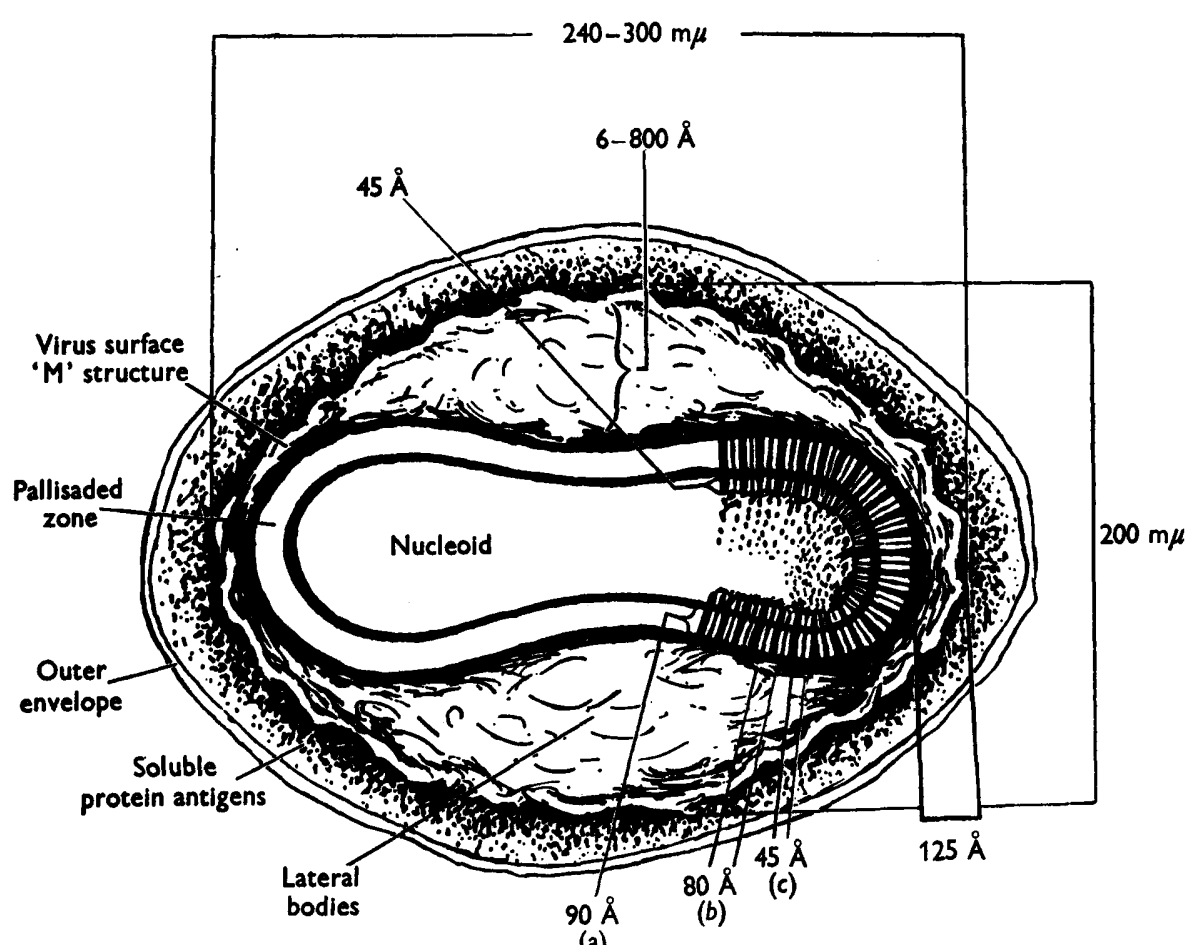

Fig. 2. Diagram of the side elevation of a virus particle showing the various layers identifiable with their suggested structure and principal dimensions.

\section{'Spherical' particles}

In all preparations of vaccinia virus and rabbit-pox virus examined a variable but small proportion (less than $10 \%$ ) of rounded particles was encountered. These particles were first seen by Sharp, Taylor, Hook \& Beard (1946) who interpreted them as being normal particles seen end-on. Our observations and measurements, however, suggest that they are spheroidal bodies of $180-210 \mathrm{~m} \mu$ diameter, sometimes with an apparent hexagonal outline (Pl. 3, fig. 13) which, by analogy with 
adenovirus, might suggest an icosahedral form (Horne, Brenner, Waterson \& Wildy, 1959). Their appearance in shadowed and negatively stained preparations indicated that they had a fine structure similar to normal particles.

\section{DISCUSSION}

Of the various techniques of examination used in the present work, negative staining undoubtedly contributed more new information than any other, but the interpretation of this information without reference to that supplied by other techniques and to the results of experimental modifications of structure can be misleading. This applies particularly to the relationships of the two predominant morphological forms $(C, M)$ and the significance of the characteristic thread structure of the $\mathbf{M}$ form. The latter has been clearly shown to be superficial, probably limited to a surface layer about $125 \AA$ thick, and cannot be taken to represent the structure of the virus as a whole. Furthermore, despite the temptation to interpret double helices in terms of DNA, it is highly unlikely that this structure includes nucleic acid. DNA comprises less than $5 \%$ of the dry weight of the virus, of which over $90 \%$ consists of protein, and it seems improbable that this genetic DNA material should be spread in a thin layer over the virus surface. It seems more likely that the thread structure is protein, but there is no direct evidence for this. The fact that the $\mathbf{M} \rightarrow \mathbf{C}$ conversion was brought about by fat solvents suggests that the impermeability of this layer to phosphotungstic acid might be due to the incorporation of lipid in the layer; this might also confer resistance to the action of proteolytic enzymes. Experiments to be reported elsewhere have shown that after ethanol treatment the virus is more susceptible to attack by trypsin. The susceptibility of the layer to desiccation, alkali and urea would also be in keeping with the presence of a lipoprotein structure. If the thread structure is in fact protein or lipoprotein, then its antigenic constitution is of the first importance since it probably represents the true constitution of the virus surface. The present work indicates that the precipitinogens extractable from the purified virus are contained in a structureless outer protein layer which is not essential to infectivity.

\section{REFERENCES}

Backus, R. C. \& Williams, R. C. (1950). The use of spraying methods and of volatile suspending media in the preparation of specimens for electron microscopy. J. appl. Phys. 21, 11.

BradLeY, D. E. (1960). Study of background structure in platinum/carbon shadowing deposits. Brit. J. appl. Phys. 11, 506.

Brenner, S. \& Horne, R. W. (1959). A negative staining method for high resolution electron microscopy. Biochim. biophys. acta, 34, 103.

Craigie, J. \& Wishart, F. O. (1936). Studies on the soluble precipitable substances of vaccinia. I. The dissociation of precipitable substances from the elementary bodies of vaccinia. J. exp. Med. 64, 803.

Crick, F. H. C. \& KENDREw, J. C. (1957). X-ray analysis and protein structure. Advanc. Protein Chem. 12, 133.

Dales, S. \& Siminovirch, L. (1961). The development of vaccinia virus in Earle's L-strain as examined by electron microscopy. J. biophys. biochem. Cytol. 10, 495.

Dawson, I. M. \& McFarlane, A. S. (1948). Structure of an animal virus. Nature, Lond. $161,464$. 
Epstein, M. A. (1958a). Structural differentiation in the nucleoid of mature vaccinia virus. Nature, Lond. 181, 784.

EPStein, M. A. (1958b). An investigation into the purifying effect of a fluorocarbon on vaccinia virus. Brit. J. exp. Path. 39, 436.

HARRIs, W. J. (1962). Device for shadowcasting and making thin films for electron microscopy. J. sci. Instrum. 39, 529.

Herzberg, K., Kueinschmidt, A., Lang, D. \& Reuss, R. (1961). Vaccinevirus und Kanarienpockenvirus elektronenmikroskopisch bei Negativkontrastierung. Naturrissenschaften, 48, 725.

Hoagland, C. L., Smadel, J. E. \& Rivers, T. M. (1940). Constituents of elementary bodies of vaccinia. I. Certain basic analyses and observations on lipid components of the virus. J. exp. Med. 71, 737 .

Horne, R. W., Brenner, S., Waterson, A. P. \& Wildy, P. (1959). The icosahedral form of an adenovirus. J. molec. Biol. $1,84$.

Morgan, C., Eluison, S. A., Rose, H. M. \& Moore, D. H. (1954). Structure and development of viruses observed in the electron microscope. II. Vaccinia and fowl-pox viruses. J. exp. Med. 100, 301.

Nagington, J. \& HoRne, R. W. (1962). Morphological studies on orf and vaccinia viruses. Virology, 16, 248.

Noyes, W. F. (1962a). The surface fine structure of vaccinia virus. Virology, 17, 282.

Noyes, W. F. (1962b). Further studies on the structure of vaccinia virus. Virology, 18, 511.

Peters, D. (1956). Morphology of resting vaccinia virus. Nature, Lond. 178, 1453.

Peters, D. (1962). Substrukturen des Vaccinevirus. 5th int. Congr. Electron Microscopy. Electron Microscopy, 2, S2. New York: Academic Press Inc.

Sharp, D. G., Taylor, A. R., Hook, A. E. \& Beard, J. W. (1946). Rabbit papilloma and vaccinia viruses and $\mathbf{T}_{2}$ bacteriophage of $\boldsymbol{E}$. coli in 'shadow' electron micrographs. Proc. Soc. exp. Biol., N.Y. 61, 259.

Williams, R. C. (1953). A method of freeze-drying for electron microscopy. Exp. Cell Res. $4,188$.

Zwartouw, H. T., Westwood, J. C. N. \& Appleyard, G. (1962). Purification of pox viruses by density gradient centrifugation. J. gen. Microbiol. 29, 523.

\section{EXPLANATION OF PLATES}

Plate 1

Fig. 1. Vaccinia virus stained with phosphotungstic acid. $M$ and $C$ forms showing the greater size and electron density of the latter. $\times 80,000$.

Fig. 2. Vaccinia virus. Section of osmic acid-fixed virus stained with lead hydroxide. The appearance of the nucleoid suggests the presence of regular internal structure. $\times 180,000$.

Figs. 3, 4. Vaccinia virus stained with phosphotungstic acid. $M$ forms showing marginal serrations and arrangement of thread structures. Looping of these to form the serrations can be seen at $A$. Fig. 4 shows, in addition, remnants of the outer envelope. $\times 170,000$.

Fig. 5. Vaccinia virus stained with phosphotungstic acid. One end of an $M$ form showing arrangement and structure of individual threads. The edges of the virus have been printed out and the dotted lines indicate their positions. B, chain-stitch appearance; $\mathbf{C}$ and $\mathbf{C}_{1}$, threads showing as a series of parallel dots. $\times \mathbf{5 5 0 , 0 0 0}$.

\section{Plate 2}

Fig. 6. Vaccinia virus stained with phosphotungstic acid. Thread structure of the $M$ form. A, B and $\mathrm{C}$ indicate appearances suggestive of coiled structure. $\times \mathbf{3 5 0 , 0 0 0}$.

Fig. 7. Vaccinia virus stained with phosphotungstic acid. Individual threads at high magnification showing appearances suggestive of coiled structure. $\times 680,000$.

Fig. 8. Vaccinia virus stained with phosphotungstic acid. $\mathrm{C}$ form showing pallisaded capsular structure at $A$ and $B . \times 250,000$. 
Fig. 9. Vaccinia virus. Self-shadowed carbon replicas of trypsin-treated virus, showing stepped collapse and pallisading of virus margin, and complex surface patterning. The upper particle shows faint radial striation continuing into the marginal pallisading, but beading appears to be absent. $\times 125,000$.

\section{Plate 3}

Figs. 10, 11. Vaccinia virus stained with phosphotungstic acid. Side elevations of $\mathrm{C}$ forms showing nucleoid and lateral bodies. The pallisaded zone of the capsule (seen also in plan at Fig. 10A) is integral with the nucleoid. At Fig. 11A, linear arrangement of the stippling in the nucleoidal area can be seen. $\times 250,000$.

Fig. 12. Vaccinia virus shadowed with carbon after treatment with trypsin and fixation in osmic acid. Surface beading is clearly visible. $\times 125,000$.

Fig. 13. Vaccinia virus stained with phosphotungstic acid. Spheroidal bodies showing $M$ type structure and tendency to hexagonal outline. $\times 200,000$.

\section{Plate 4}

Fig. 14. Vaccinia virus stained with phosphotungstic acid. Intermediate form following trypsin treatment. $C$ structure is visible at $A$. At B, M structure appears to overlap $C$ structure. $\times 230,000$.

Fig. 15. Vaccinia virus stained with phosphotungstic acid. $M$ form after treatment with trypsin for $2 \mathrm{hr}$; 证 indication of digestion of thread structure.

Figs. 16, 17. Vaccinia virus shadowed with carbon and platinum. Unfixed virus sprayed at room temperature. Collapse of the virus has revealed a wrinkled surface structure, resembling a membrane, overlying the beaded structure. $\times 140,000$.

Fig. 18. Vaccinia virus stained with phosphotungstic acid. Group of $\mathrm{C}$ forms after treatment of virus on the grid with trypsin followed by saturated urea solution. $\times 60,000$. 
Journal of General Microbiology, Vol. 34, No. 1

Plate 1

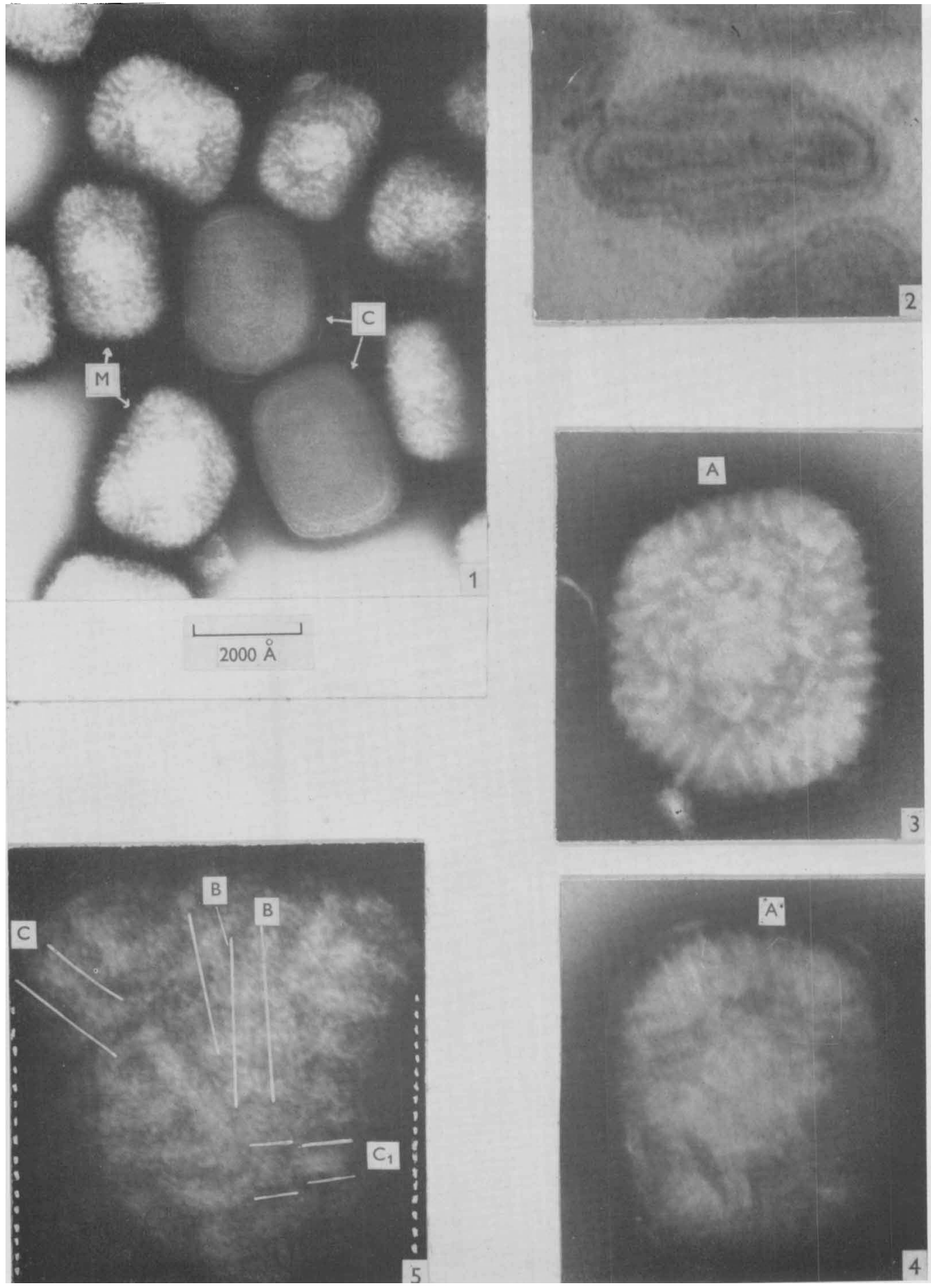

J. C. N. WESTWOOD AND OTHERS

(Facing $p .78$ ) 
Journal of General Microbiology, Vol. 34, No. 1

Plate 2
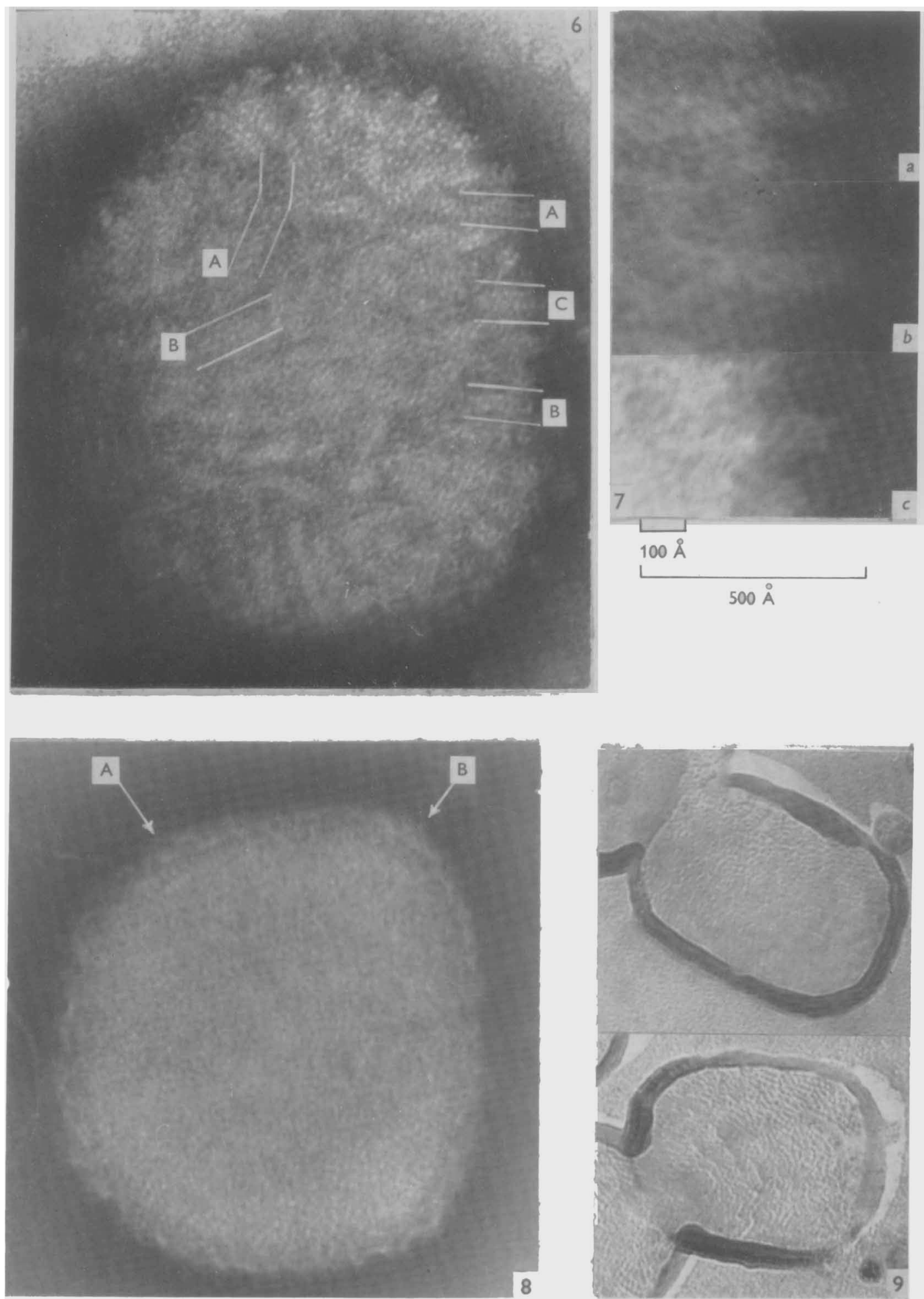

J. C. N. WESTWOOD AND OTHERS 

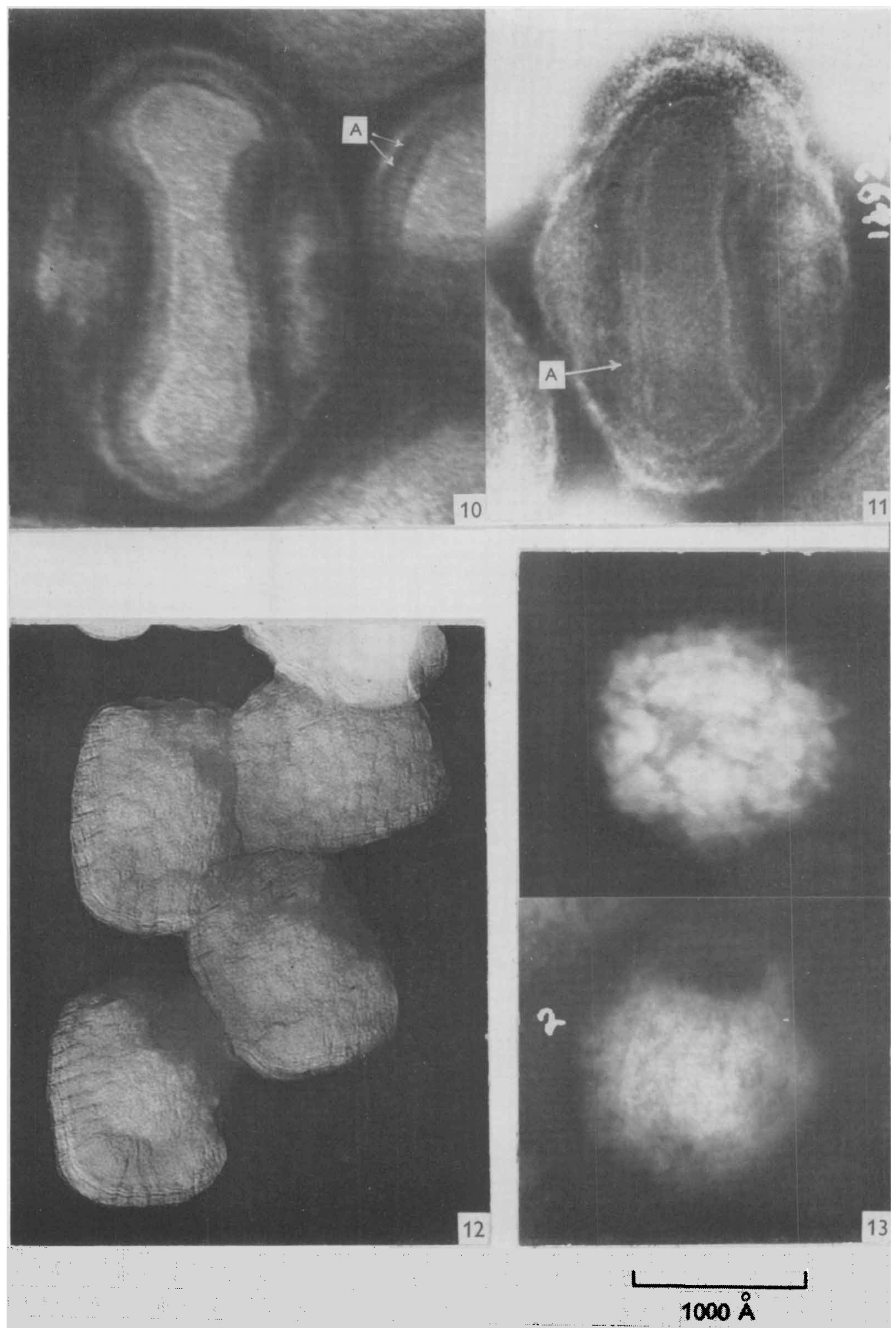

J. C. N. WESTWOOD AND OTHERS 
Journal of General Microbiology, Vol. 34, No. 1

Plate 4
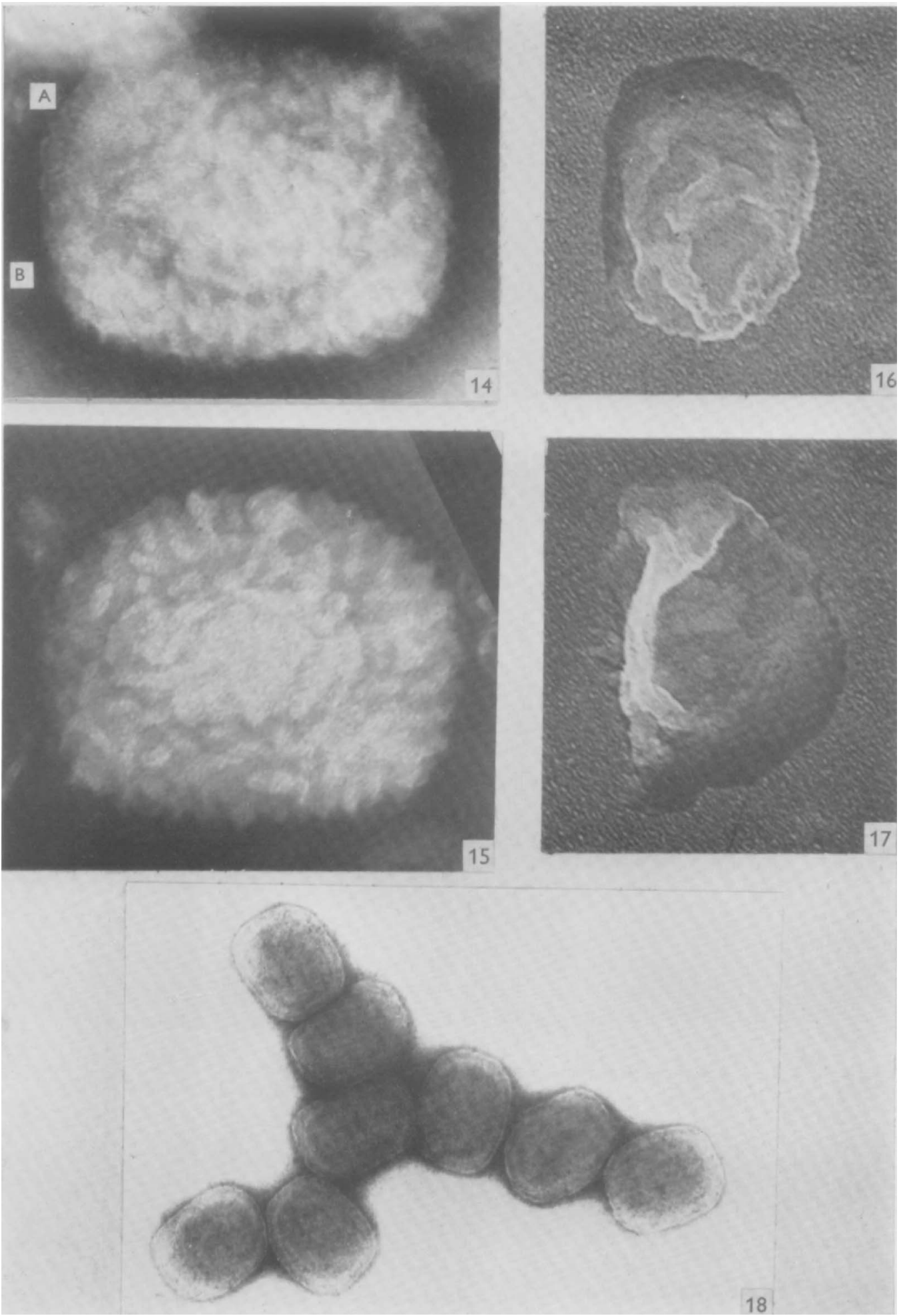

J. C. N. WESTWOOD AND OTHERS 